\title{
A doctor, a friend, and mortality
}

\author{
Stephen B Hanauer
}

In my editorials l've written about numerous personal experiences, including family and professional mishaps. Unfortunately, the life experience I'm writing about this month relates to death. Having been out of medical school for 30 years, as an internist and gastroenterologist, death and dying are not unfamiliar to me-from a professional standpoint. On a personal level, I am fortunate enough to have most of my immediate family intact. The vast majority of my close friends are healthy, as are their children. Mortality has remained, for the most part, at a professional distance.

Of course, as I presume is the case for many of us, I've seen friends (not family!) as patients. Several years ago a friend was referred to me for a colonoscopy by his internist. Happily, the evaluation did not identify significant disease. We continued to socialize and my friend remained healthy overall. He underwent a repeat colonoscopy 3 years later: again there were no significant findings and he continued to appear well through his birthday 1 month later. His symptoms were not progressive and responded to medical treatment. A month after his birthday, however, the internist discovered that my friend had abnormal liver enzyme levels, and further work-up revealed that he had metastatic liver cancer. Biopsies confirmed a diagnosis of undifferentiated adenocarcinoma.

It was not difficult to predict the course that the disease would take. Almost exactly
This

experience

has brought

the concept

of life and

death home to

me at a much

more personal

level...

SB Hanauer is Editorin-Chief of Nature

Clinical Practice

Gastroenterology

\& Hepatology.

\section{Competing interests}

The author declared no

competing interests.

www.nature.com/clinicalpractice doi:10.1038/ncpgasthep0949
3 months after the diagnosis was made my friend passed away. What had started out as a social relationship turned into a close personal relationship, with almost daily conversations helping to guide the family through diagnostic procedures, chemotherapy, one horrific 5-day hospitalization, and eventually homecare. The social friendship between our families evolved into a new form of intimacy.

Although there were no emotional 'ups' during these months, the inevitable decline of my friend brought his family together in an amazing way. His children returned home from their out-of-town studies and took charge. They surrounded their parents with continuous loving care and devotion of the kind that I had not previously witnessed, nor ever expected to. They became medical advocates and protectors. In my friend's last days, his children provided love and comfort and he was never alone. Even while he was 'comatose' he responded to them, and they to him.

I've observed our friends and families grow, marriages, and births, but I now have a much better understanding of the cycle of life. It gives me great solace to know that my friend will live on through his children, and that they rose to such great heights during his illness. This experience has brought the concept of life and death home to me at a much more personal level, along with the realization that immortality is achieved through our children and their memories. 